\title{
A MONTANHA QUE GUARDA OS JARDINS DO RIO: A PERCEPÇÃO DE RUDYARD KIPLING SOBRE O BRASIL
}

\author{
Adriana Oliveira da Silva / CAPES \\ Mestranda em Letras pela UNIFESSPA \\ Mayara da Conceição Gonçalves Carvalho / CAPES \\ Mestranda em Letras pela UNIFESSPA \\ Paulo da Silva Lima \\ Professor Doutor em Estudos Linguísticos UNIFESSPA
}

\section{RESUMO}

O referido estudo tem o objetivo de fazer uma reflexão sobre a percepção de Rudyard Kipling a respeito do Brasil e do povo brasileiro na crônica A Montanha que Guarda os Jardins do Rio. O texto, em questão, pertence ao livro As Crônicas do Brasil, a obra foi publicada inicialmente em 1927 e traduzida em uma edição bilíngue em 2006. Possui sete crônicas que relatam as impressões de Kipling durante sua viagem pelo país na mesma data de publicação. Na segunda década do século $\mathrm{XX}$, o Brasil vive um momento literário moderno, com influência das Vanguardas Europeias. A estrutura da obra apresenta um padrão, todas as crônicas são precedidas por um poema que a ilustra. Os textos apresentam registros de aspectos de Pernambuco, Bahia, São Paulo e Rio de Janeiro. A análise da percepção do autor dar-se à luz dos conhecimentos desenvolvidos por Machado (2000), Pinto-Correa (2003), entre outros.

Palavras-chave: Literatura de Viagens, Kipling, A Montanha que Guarda os Jardins do Rio.
The following research has the purpose of making a reflection on Rudyard Kipling's perception about Brazil and brazilian people on the chronic The Mountain that Runs the Gardens of Rio. The text in question belongs to the book Brazilian Sketches, the work was published initially in 1927 and translated for a bilingual edition in 2006. It has seven chronicles that report Kipling's impression during his country trip on the same date of publication. In the second decade of the 20th century, Brazil lived a modern literary moment, that was influenced by the European Vanguard. The work's structure presents a pattern, all the chronicles are preceded by a poem that illustrate it. The text presents records of aspects from Pernambuco, Bahia, São Paulo e Rio de Janeiro . The analysis of author's perception happens at the light of knowledge developed for Machado (2000), Pinto-Correa (2003), among others.

Keywords: Trip Literature, Kipling, The Mountain that Keeps the Rio's Gardens

\section{ABSTRACT}


A arte de viajar é uma arte de admirar, uma arte de amar.

INTRODUÇÃO

(Cecília Meireles)

A Montanha que Guarda os Jardins do Rio é uma das crônicas da coletânea do livro As Crônicas do Brasil de Rudyard Kipling (1865-1936), escritor britânico nascido na Índia, seu grande reconhecimento internacional aconteceu em 1907 ao receber o "(...) Prêmio Nobel de Literatura, é autor dos mundialmente conhecidos Mowgli, o Menino Lobo (O Livro da Selva) e o Homem que Queria Ser Rei (...)" ${ }^{\prime 1}$. Escreveu várias obras, dentre elas, depoimentos sobre suas viagens, Literaturas de Viagens.

Pensar em Literatura de Viagens é, antes de mais, admitir que há um conjunto de textos, que há viagem, temas, motivos e formas que, na sua globalidade, se identificam como um conjunto autônomo, distintos de outros conjuntos textuais.

(...) Obviamente, a Literatura de Viagens não tem o monopólio das viagens. Também elas abundam na ficção de costumes, na história e em outras. Mas nesta, o mais importante é o estatuto genelógico da viagem como deslocação, não participando das características semiológicas, históricas, de edição e de recepção que são próprias da Literatura de Viagens. (CRISTÓVÃO, 2002, p. 15)

A obra bilíngue relata de forma literária, a passagem do autor pelo país que durou cinco semanas, a mesma foi “(...) publicada inicialmente em sete artigos no Morning Post entre 29 de novembro e 20 de dezembro de 1927, As Crônicas do Brasil foram reunidas nas Edições Sussex, que eram edições de luxo destinadas a colecionadores" ${ }^{2}$ e traduzidas em 2006 por Luciana Salgado, que tece algumas notas sobre os textos. Pode-se afirmar que de acordo com a classificação feita por Cristóvão (2009) a obra em questão, pertence à uma tipologia possível de literatura de viagens. De acordo com a estrutura da obra e objetivo da

\footnotetext{
${ }^{1}$ Informação contida na contracapa da obra.

${ }^{2}$ Informação contida na contracapa da obra.
} 
viagem, ela pode ser compreendida como uma viagem de conhecimento do país, nessa tipologia se enquadram as Viagens na Minha Terra de Almeida Garrett. Como afirma o título, a obra é composta por crônicas e sobre essa composição textual Cristóvão (2009, p. 17) diz que "não só a crônica é o molde narrativo privilegiado, mas também é novo o seu andamento rápido e de melhor liberdade no uso da linguagem oral e coloquial"

A obra As Crônicas do Brasil possui sete crônicas que relatam as impressões de Kipling sobre o Brasil e o povo brasileiro: Em A Busca da Beleza: Viagem ao Exterior, o autor faz comentários a respeito do início da viagem, esclarece sobre os objetivos e expectativas, fica fascinado com a interação de alguns idiomas em um mesmo local e faz algumas considerações sobre a Bahia e Pernambuco; Em A Montanha que Guarda os Jardins do Rio, crônica analisada em questão, o autor aborda os traços da cidade do Rio de Janeiro; Em $O$ Deus dos Relâmpagos: Como a Energia Chegou a São Paulo, o autor demonstra o deslumbre com a produção da energia elétrica no país; Em Adão e a Serpente: Visita a uma Moderna Fazenda de Serpentes, Kipling tece algumas observações sobre o Instituto Butantan ${ }^{3}$, em que na época “(...) um surto de peste bubônica que se propagava no porto de Santos em 1889, levou o governo a adquirir a Fazenda Butantan para instalar o laboratório de produção de soro antipestoso (...)" (KIPLING, 2006, p. 140); Na crônica A São Paulo do Pós Guerra: Uma Fazenda de Café do Interior, tece comentários sobre a cidade de São Paulo, uma fazenda de café, mais especificamente sobre o sabor do café “(...) de modo algum era tão importante como o sabor e a mistura do café. Desse café, basta dizer que descobri nunca ter provado café antes. Pode-se beber a substância mágica em grandes xícaras, cada uma melhor que a

\footnotetext{
${ }^{3}$ Atualmente é o principal produtor de imunobiológicos do país. http://www.butantan.gov.br/Paginas/default.aspx acesso em 31/05/2018.
} 
anterior, e ter um sono abençoado mais tarde (...)" (KIPLING, 2006, p. 89); Em O Romance da Construção da Estrada de Ferro: Uma Escala de Seiscentos Metros, em que contempla a ferrovia “A San Paulo (Brazilian) Railway Company, companhia formada pelo Barão de Mauá e investidores ingleses em 1858" (KIPLING, 2006, p. 141); Em Um Mundo à Parte Um Povo Com o Seu Próprio Deus: Como a Força dos Fundadores Sobrevive, o autor faz algumas críticas sobre as contradições que observou em sua passagem pelo país, contudo, finalizou a obra realçando a beleza do Brasil.

Tais registros de aspectos brasileiros foram observados em Pernambuco, Bahia, São Paulo e Rio de Janeiro, este último lugar, no período da passagem do escritor, em 1927, era a capital federal do país. A estrutura da obra apresenta um padrão, todas as crônicas são precedidas por um poema que a ilustra, composto por textos com essência subjetiva do autor.

Percebe-se também que essa obra de Kipling é influenciada pelas Vanguardas Europeias, sobretudo, pelo futurismo. Esse momento intelectual foi influenciado pelo contexto histórico, ou seja, pelo período pós Primeira Guerra Mundial, pelas transformações tecnológicas da virada do século, que deslocaram e aceleraram o olhar do homem moderno, com isso, novas maneiras de o homem perceber a realidade. (PROENÇA, 2008). Tal constatação pode ser evidenciada em toda a obra, observa-se com clareza na crônica O Deus dos Relâmpagos: Como a Energia Chegou a São Paulo, através do deslumbramento com a produção de energia “(...) o Brasil, sentado sobre uma ilimitada energia elétrica, a venderá entre vinte e cinco ao Norte e sessenta ao Sul em ambos os lados do continente (...) para algum lugar distante da África" (KIPLING, 2006, p. 57). Nessa situação, o autor foi encarado 
como um "visionário", pois o engenheiro com quem dialogava percebeu que os comentários ali realizados eram resultados de uma grande admiração com a produção da energia elétrica.

Contudo, o referido artigo tem o objetivo de fazer uma reflexão relativa à percepção de Rudyard Kipling sobre o Brasil e o povo brasileiro, somente na segunda crônica da obra, $A$ Montanha que Guarda os Jardins do Rio. Desse modo, além dos constituintes habituais, com resumo, introdução e considerações finais, o texto segue com a abordagem da contextualização da obra e com a reflexão sobre a percepção de Rudyard Kipling, na crônica em questão. O estudo da percepção do autor dar-se à luz dos conhecimentos desenvolvidos por Machado (2000), Pinto-Correa (2003), Meireles (1999), entre outros.

\section{CRÔNICAS DO BRASIL: CONTEXTUALIZAÇÃO DA OBRA}

A viagem inicia em Southampton, cidade portuária localizada na costa sul da Inglaterra. Ainda no cais, o escritor fica admirado com a interação entre duas línguas, o português e o espanhol, com a possibilidade de um italiano "aprender o português instrumental em duas semanas" (KIPLING, 2006, p. 15) e com o fato desses povos serem culturalmente ligados, devido ao latim. As impressões do turista sobre o país são expostas de forma literária, com títulos subjetivos e poemas que antecedem cada uma das crônicas.

Nesse contexto, é interessante sobressaltar a diferença entre o turista e o viajante. 0 primeiro, respectivamente, possui todo o seu itinerário calculado, sabe informações suficientes do que deve ser observado, "seu destino é caminhar sobre as superfícies das coisas, como do mundo, com a curiosidade suficiente para passar de um ponto a outro (...) sem apego nem compromisso, uma vez que já sabe, por experiência, que há sempre uma paisagem por trás da outra". O segundo não tem o roteiro de viagem calculado, sendo assim, 
não consegue contemplar o que é para ser visto, o que habitualmente todos veem e por isso, "sente uma vaga humilhação, por não poder ver assim facilmente nada, por serem seus olhos tão lentos e, deslizar pelas cores, pelas sombras, pela qualidade das pedras, pelos seus relevos (...)" (MEIRELES, 1999, p. 101-102)

A ótica dele se aproxima mais de um turista pelo fato de ter um olhar muito idealizado sobre o Brasil. Desse modo, produz uma imagem literária sobre o Brasil que reflete um olhar de um estrangeiro deslumbrado com os aspectos naturais e culturais do país, além da visão ser influenciada pelo momento cultural moderno. A imagem literária, segundo Machado e Pageaux (2000), pode ser compreendida como todo o conjunto de ideias do escritor-observador que interfere no processo de literarização, bem como o meio cultural que reflete a sociedade, isso implica por parte do investigador observar o processo de produção, difusão e todo o material cultural que compõe ou influencia a obra.

(...) A imagem literária pode ser definida como sendo um conjunto de ideias sobre o estrangeiro incluídas num processo de literarização e também de socialização, quer dizer, como elemento cultural que remete à sociedade. Essa nova perspectiva obriga o investigador a ter em conta não só o texto literário em si, mas também as condições de sua produção e da sua difusão, bem como todo o material cultural com o qual se escreve, pensa e vive. (...) (MACHADO e PAGEAUX, 2000. p. 57)

A imagem literária construída pelo escritor na crônica em análise tem como cenário a cidade do Rio de Janeiro, capital federativa do país na época e que estava vivendo um momento cultural moderno, iniciado em 1922 com a Semana de Arte Moderna. Portanto, constata-se nessa imagem literária dois aspectos fundamentais: um eu, no caso a visão de um estrangeiro, Kipling, escritor britânico em relação ao outro, o Brasil e o povo brasileiro. Ainda de acordo com os mesmos estudiosos, toda imagem provém de uma tomada de 
consciência que procede do distanciamento entre duas realidades, o eu e o outro, ou seja, Kipling e o Brasil.

(...) qualquer imagem procede de uma tomada de consciência, por menor que seja; procede de um <<Eu〉> em relação a um <<algures>>. A imagem é, portanto, o resultado de uma distância significativa entre duas realidades culturais. Ou melhor: a imagem é a representação de uma realidade cultural estrangeira através do qual o indivíduo ou grupo que a elaboram (ou que a partilham ou que a propagam) revelam e traduzem o espaço ideológico no qual se situam. (MACHADO e PAGEAUX, 2000. p. 58)

Portanto, a imagem literária na obra As Crônicas do Brasil é a representação da realidade na ótica do escritor britânico que mostra e traduz o espaço natural, cultural e ideológico das terras brasileiras por onde passou. Entretanto, o estudo em questão aborda essa representação em uma crônica específica: A Montanha que Guarda os Jardins do Rio.

\section{A MONTANHA QUE GUARDA OS JARDINS DO RIO}

Lá habitam passarinhos, meus conterrâneos - Coisinhas preciosas menores que abelhas (Uma Canção de abelhas)

A crônica A Montanha que Guarda os Jardins do Rio é a segunda da coletânea da obra Crônicas do Brasil. Assim como as demais, é precedida por um poema: Uma Canção de Bananas - como pode ser verificada na epígrafe e no fragmento que segue abaixo, que a ilustra, e revela principalmente o fascínio com a diversidade da fauna e da flora; além da facilidade de acesso e consumo de tais elementos; e a coexistência com o meio urbano e com a vida moderna.

Lá, a terra vermelha produz e murmura, meus conterrâneos

Dia e noite, em exuberante fecundidade,

E a flor e a Serpente estão livres e despertas, 
Como se estivessem na árvore do Paraíso

(Quando a Primeira Lua Prateou por entre a Árvore)...

(KIPLING, 2006. p. 29)

A quinta estrofe do poema, Uma Canção de Bananas - composição disposta em seis estrofes - relata a fertilidade e a diversidade do que é produzido em terras brasileiras, além de enfatizar a facilidade do consumo, mesmo que esse seja ilícito, em certo momento da crônica, em A Montanha que Guarda os Jardins do Rio, o próprio autor se incluiu como infrator por consumir produto não permitido: “(...) Há pessoas que caçam, cortam-lhes as asas com tesouras, como retalhos, e as fincam sob cinzeiros de vidro para vendê-las aos turistas, aos quais - Que Alá me perdoe! - eu me incluo como infrator." (KIPLING, 2006. p.39).

O título da crônica é outro fator que caracteriza o aspecto literário desse texto, assim como, as demais da obra. Em A Montanha que Guarda os Jardins do Rio, o termo Montanha pode ser considerado como uma palavra fantasma, segundo os conceitos defendidos por Machado e Pageaux (2000), ou seja, são palavras que possuem mais polissemia, nesse caso, o sentido não está restrito à forma de relevo. A montanha deixa apenas de fazer parte do cenário, como relevo. Pode ser compreendida que sua grandiosidade é responsável pela "guarda", "segurança" dos Jardins, além de revelar o deslumbramento do escritor com a paisagem natural da cidade.

“(...) Mas, veja! Se olhar para aquela montanha iluminada no topo, verá que, antes, ela estava atrás de nós.” A montanha permaneceu imóvel, seguíamos a 35 nós. "Agora ela irá correr ao nosso lado". Obediente, a elevação fez isso mesmo, de imediato. "Agora seguirá em frente. Depois, esperará por nós no fim da próxima baía". A montanha nos 
ultrapassou e então se deteve naquele ponto exato, sem demonstrar sinal de fadiga. Antigamente, uma pessoa seria queimada na fogueira se fizesse esse tipo de bruxaria. (KIPLING, 2006. p. 35)

Na referida crônica, Kipling relata as suas observações sobre o Rio de Janeiro, na época, capital federativa do país. Descreve a cidade e o povo brasileiro com admiração, comenta sobre o relevo, a favela, os banhistas, o carnaval, o trânsito e a diversidade natural. De acordo com Pinto-Correia (2003) pode-se afirmar que tais descrições foram realizadas com um olhar ingênuo e deslumbrado:

Em lugar privilegiado, os narradores - consideremo-los mais perto ou mais longe da missão referencial de observadores e/ou participantes, ou intervenientes da narrativa-descrição, individuais ou colectivos - deixam transparecer a <<ingenuidade>> do seu olhar através principalmente do <<deslumbramento >>.

A novidade, a grandeza ou a beleza das paisagens e gentes parecem não poder ser avaliadas, pelo menos num primeiro momento por qualquer outra preocupação senão a de contemplar, presenciar e anotar. (...) (PINTO-CORREIA, 2003. p. 17)

Portanto, pode-se afirmar que o deslumbramento de Kipling com o Rio de Janeiro é perceptível em toda a crônica A Montanha que Guarda os Jardins do Rio, o comportamento ingênuo, que se dá principalmente pelo deslumbramento com a cidade, prevalece no olhar “(...) puro, autêntico, livre, verdadeiro (conjunção do <<ser>> e do <<parecer >>), não escravo dos preconceitos e das opressões anteriores. Opondo-se ao $<<$ olhar cobiçoso $>$, o <<interessado>> e o <<interesseiro >> ou <<ambicioso >>(...)" do escritor. (PINTO-CORREIA, 2003. p. 17) 
O autor evidencia sua admiração pelo relevo do Rio em alguns momentos da crônica. Ao percorrer Copacabana - no período da passagem do autor, nos anos vinte, o local era pouco desenvolvido - “(...) isso não é cidade. É apenas um dos subúrbios", a montanha fez despertar o olhar para uma favela da região, atualmente chamada de comunidade: “(...) as montanhas elevadas, que não podiam ser vistas, apenas sentidas; e as casas iguais às de duendes, que se expunham na claridade. As casas combinavam com a irrealidade de tudo aquilo (...)" (KIPLING, 2006, p. 33-35). O modo como o autor nomeou as moradias, casas de duendes, não foi depreciativo, mas sim o tamanho das moradias em comparação à grandiosidade da montanha.

(...) Pude ver o que acontecia às pequenas casas, naquela luz, ao desbotarem seus azuis, amarelos, rosas e magentas; flores vermelho-sangue ou douradas, em árvores e arbustos, conferiam a tudo beleza e efeito. Então começa a se entender com bom senso das casas de duendes da noite anterior, na praia de Copacabana, e que (isso deve ser segredo dos latinos) diante a autêntica luz do sol, deve-se enxergar. (...) Tudo estava no lugar em que deveria estar, e tudo crescia com naturalidade em uma atmosfera apropriada(...)

(KIPLING, 2006, p. 39)

Como pode se verificar, no dia posterior, por meio de uma visita ao local, o autor pode observar de perto as casas de duendes, essas foram descritas de maneira deslumbrada em relação àquele cenário, em que a natureza e a urbanização conviviam em harmonia e que se completavam. Ainda na mesma localidade, o autor teve contato com uma festividade marcante do país, o Carnaval, “(...) onde alguns carros estavam repletos de pessoas fantasiadas, alegres e cantantes. 'Isso é porque o Carnaval é daqui a uma semana. Eles estão se preparando para isso (...)'"' (KIPLING, 2006, p. 39). 
Observa-se um olhar ingênuo por toda a obra, isto é, o modo como o sujeito-observador vê o mundo, registra do mesmo modo aquilo que ele viu. O registro revela o seu subjetivo, além de mostrar uma tentativa de compreensão daquilo que está fora. Constata-se nas observações feitas pelo escritor a predominância da relação de filia em sua representação do Outro, no caso do Brasil e do povo brasileiro. Nesse tipo de posicionamento em relação ao outro “(...) a realidade estrangeira é tida pelo escritor pelo grupo como sendo absolutamente superior à cultura nacional de origem (...)" (MACHADO e PAGEAUX, 2000, p. 73).

(...) Há, talvez, águas mais adoráveis em algum outro lugar, mas nem Sidney, nem a Cidade do Cabo, que sempre julguei magníficas, cada uma a seu modo, comparam-se a esta em tamanho - o que no fim não importa muito - ou pela indescritível diversidade, coloração, amplitude e esplendor do cenário. (...) KIPLING, 2006. p. 35)

Ele faz comparação com lugares conhecidos e descreve com fascínio o cenário brasileiro. Em certo momento da crônica, Kipling (2006, p. 37) afirma que o deslocamento é barato em relação às belezas locais: “(...) é barato demais para um lugar evidentemente em contato com os Deuses, e que, como também, é evidente resguardava suas próprias terras aprazíveis."

Quanto à modernidade, o escritor demarca a crônica com expressões adjetivadas, tais como, “(...) constelações de estrelas opacas sem controle (...)", que expressa a sua contemplação com as luzes, com o convívio harmônico da natureza com o meio urbano. 0 mesmo aspecto pode ser percebido em um “(...) mundo de luzes oferecidos de repente sem fronteira, entre vultos de construções sem fronteiras (...)" (KIPLING, 2006, p. 31), em que se 
pode constatar o fascínio com as luzes da cidade. O auge do deslumbre com a energia elétrica no país acontece em sua passagem por São Paulo, quando visita uma usina hidrelétrica, relatada na terceira crônica da obra: O Deus dos Relâmpagos: Como a Energia Chegou a São Paulo. O fascínio com a eletricidade pode ser constatado desde a expressão do título "Deus dos Relâmpagos", que pode ser considerada uma expressão fantasma, segundo os conceitos de Machado e Pageaux (2000), que sugere uma amplitude de significados relacionados ao domínio da produção da energia elétrica.

Em suas observações constata-se também certo estranhamento, e ao mesmo tempo, exaltação em relação à velocidade dos meios de transportes, relata isso por meios de algumas expressões, tais como: “(...) demoníacos ônibus motorizados, cujos estrondos cotidianos eu mais tarde confundi com o barulho de um aeroplano, vindo do alto de uma colina(...)"; pode-se observar também em “(...) ainda iluminada pela luz insolente e toda poderosa, mas - é preciso agradecer aos deuses - inteira aromatizada por carros velozes $(\ldots)$ " e em o "(...) mundo inteiro seguia conosco em carros, todos repletos de pessoas sem chapéus, correndo na máxima velocidade"(KIPLING, 2006, p. 31-33). Esse olhar voltado para a energia elétrica, meios de transporte em máxima velocidade, pode-se afirmar que está conciliada à Vanguarda Futurista. Nesse contexto Bortulucce $(2009$, p. 62) enfatiza que:

Mais do que a exaltação dos grandes centros urbanos, mais do que o culto à máquina, à força mecânica, o legado maior do Futurismo reside no seu projeto de arte integrada à vida, um projeto envolvido com a questão do tempo. Neste sentido, o conceito de velocidade transcendeu a ideia de uma qualidade somente do automóvel; a simultaneidade tão proclamada nos manifestos da pintura vazou pelas bordas do quadro e imprimiu-se nas atividades cotidianas; a vida moderna tornou-se a máquina de barulhos de Russolo; a maior engrenagem é a própria existência (...) 
O autor observa tais detalhes deslumbrado, principalmente pela visão futurista mencionada anteriormente. Essa vanguarda artística trazia características de rompimento com o passado, além da exaltação de tudo o que era considerado novo, entenda-se por novo, as descobertas e tecnologias que movimentavam o mundo naquela época. 0 movimento futurista foi disseminado por meio de manifestos, e no seu primeiro, publicado no jornal francês Le Figaro, o italiano Filippo Tommasio Marinetti, aponta um de seus anseios:

Nós declaramos que o esplendor do mundo se enriqueceu com uma beleza nova: a beleza da velocidade. Um automóvel de corrida com seu cofre adornado de grossos tobos como serpentes de fôlego explosivo... um automóvel rugidor, que parece correr sobre a metralha, é mais belo que a Vitória de Samotrácia. (TELES, 1983. p. 92)

Outro aspecto que chama atenção são os banhistas, que em alguns momentos geram até estranhamento no ponto de vista do escritor, pois considerou engraçado o banhista estar todo molhado, em um país que possui a cultura de tomar banhos diariamente e fugir da chuva. Contudo, o autor assiste a tudo e considera divertido, pode-se afirmar que não foi gerado um juízo de valor. Nesse contexto, é possível afirmar que houve uma representação cosmopolita de representação do outro, segundo os parâmetros abordados por Machado e Pageaux (2000, p. 76), ou seja, que “(...) não se põe o problema do juízo positivo ou negativo, pelo menos aparentemente de maneira nítida e imediata (...)"

(...) Nunca tendo ouvido que famílias inglesas banhavam-se próximo ao aterro, aquilo me chamou atenção. Como também um cavalheiro com trajes de banho em sua motocicleta; e duas garotas, tão molhadas pelo mergulho em algum lugar mais adiante, que foram postas com razão nos estribos do carro da família, que elas seguravam como se fossem o brasão da família, enquanto conversavam em seus roupões úmidos, em lados opostos. Então alguém lembrou que neste clima ameno as pessoas se banham com frequência, e em todo lugar onde a água é segura: o que conta para a 


\begin{abstract}
limpeza das massas das multidões locais. Foi agradável notar uma vez como a chuva é detestável para pessoas nascidas e educadas de maneira apropriada. Um único borrifo as obriga cobrirem-se o máximo que puderem; e eu assisti, divertido, a uma família inteira de banhistas ser vencida por uma chuvinha leve e fugir apressada para refugiar-se sob as árvores. (KIPLING, 2006, p. 37)
\end{abstract}

Kipling tece comentários sobre as belezas naturais com deslumbre acentuado pela expectativa de contemplar a flor vitória-régia e o pássaro jacara: “A maioria de nós tem um ideal. O meu, acariciado desde a infância, era de ver a flor vitória-régia em seu habitat, e se possível, também aquele pássaro de dedos muito longos (Jacara, deve ser o nome) (...)". Contudo, a curiosidade em conhecer a diversidade das flores não foi satisfeita, pois o motorista de táxi “(...) apesar de possuir maneiras que servem de exemplo a um príncipe, não foi de muita ajuda. Ele conhecia o Jardim, mas as flores - não senhor (...)" (KIPLING, 2006, p. 37 - 39). A contemplação do pássaro só foi possível na manhã do dia seguinte, onde se encontrava preso em uma gaiola, segundo as palavras do autor (2006, p. 41), “(...) onde vendem prodígios (...)".

O escritor encerra o texto A Montanha que Guarda os Jardins do Rio fazendo comentários à crônica seguinte da obra, O Deus dos Relâmpagos: Como a Energia Elétrica chegou a São Paulo. O próprio termo do título "Deus do Relâmpago" revela um olhar deslumbrado do autor referente à energia.

\title{
CONSIDERAÇÕES FINAIS
}

Transitar pelo Brasil da segunda década do século XX, por meio da percepção de Rudyard Kipling permite ter uma concepção sobre o país e do povo brasileiro, mais especificamente do Rio de Janeiro, na época capital federativa do país, através do olhar de escritor britânico no período da época moderna. Tal análise foi realizada através da crônica A 
Montanha que Guarda os Jardins do Rio, o texto pertence ao livro As Crônicas do Brasil, publicada inicialmente em 1927 e traduzida em uma edição bilíngue em 2006.

Por meio desse estudo, observa-se a visão de um turista que produz uma imagem literária sobre o Brasil, com um olhar de um estrangeiro deslumbrado com os aspectos naturais e culturais do país, além da visão ser influenciada pelo momento cultural moderno, pelas Vanguardas Europeias, sobretudo a do Futurismo. O deslumbre é evidenciado em cada detalhe observado pelo escritor, que descreve de forma literária a cidade do Rio de Janeiro e o povo brasileiro com admiração, faz comentários deslumbrados, que caracteriza o olhar ingênuo do autor, sobre o relevo, a favela, os banhistas, o carnaval, o trânsito e a diversidade natural.

Portanto, um estudo sob essa perspectiva é importante tanto para conhecer um local em um determinado momento social e histórico, quanto para visualizar esse mesmo local por meio da ótica de um estrangeiro, um turista, no caso em questão, viver a cidade do Rio de Janeiro da segunda década do século XX por meio da crônica A Montanha que Guarda os Jardins do Rio, de Rudyard Kipling.

\section{REFERÊNCIAS}

BORTULUCCE, Vanessa Beatriz. O Centenário do Futurismo: uma estética do tempo. V Encontro de História da Arte- IFCH / UNICAMP, 2009.

CRISTÓVÃO, Fernando. Introdução: Literatura de Viagens: da Tradicional à Nova e à Novíssima Marcas e Temas. Coimbra: Almedina, 2009.

Para uma Teoria da Literatura de Viagens. In: Condicionantes Culturais da Literatura de Viagens. Coimbra: Almedina, 2002.

KIPLING, Joseph Rudyard. As Crônicas do Brasil. Edição Bilíngue. Tradução e Notas de Luciana Salgado. São Paulo: Landmark, 2006. 
MACHADO, Álvaro Manuel e PAGEAUX, Daniel-Heuri. Da Imagem ao Imaginário. In: Da Literatura Comparada à Teoria Literária. 2 ed. Lisboa: Presença, 2000.

MEIRELES, Cecília. Roma, Turistas e Viajantes. In: Crônicas de Viagem. Vol. 2. Rio de Janeiro: Nova Fronteira, 1999.

PINTO-CORREA, João David. Deslumbramentos, Horror e Fantasias: O Olhar Ingênuo na Literatura de Viagens. In: O Olhar do Viajante - Dos Navegadores aos Exploradores. Coimbra: Almeida, 2003.

PROENÇA FILHO, Domício. Estilos de época na literatura. São Paulo: Ática, 2008

TELES, Gilberto Mendonça. Vanguardas europeias e Modernismo brasileiro. Petrópolis: Vozes, 1983.

Artigo recebido em: 31 de maio de 2018. Artigo aprovado em: 08 de julho de 2018. 